\title{
Thermophysical Properties of Methane: Virial Coefficients, Vapor and Melting Pressures*
}

\author{
Robert D. Goodwin** \\ Institute for Basic Standards, National Bureau of Standards, Boulder, Colorado 80302
}

(June 1, 1970)

\begin{abstract}
For use in the computation of thermodynamic properties in gaseous and liquid states at $T<300 \mathrm{~K}$ there are given concise descriptions of the properties named in the title. Numerous published data on methane are combined with some new analytical expressions which give more acceptable behavior than previously could have been achieved.
\end{abstract}

Key words: Melting pressures; methane; thermophysical properties; vapor pressures; virial coefficients.

\section{List of Symbols}

Subscripts $c$ and $t$ refer to critical and triple points.

$a, b, c, d$, $A, B$ $B_{i}, C_{i}$, coefficients for eq (4). coefficients for eq (6). coefficients for eqs $(2,3)$.

$B(\tau), C(\tau)$, the "virial coefficients."

$d, \quad$ density

$\Delta$

$\Delta$ any relative deviation, $\left(y / y_{\text {calc }}-1\right)$. exponent in various expressions. the Joule.

the liter.

$16.042 \mathrm{~g}$ of methane. pressure, $1 \mathrm{~atm}=0.101325 \mathrm{MN} / \mathrm{m}^{2}$. the gas constant, $8.3143 \mathrm{~J} /(\mathrm{mol} \mathrm{K})$. $d / d_{c}$, density reduced at $d_{c}$. temperature, K on the IPTS (1968). $T / T_{c}$, temperature reduced at $T_{c}$. $1 / d$, molal volume.

defined argument in various equations. dependent variable in eq (6).

$P v / R T$, the "compressibility factor."

\section{Introduction}

It appears likely that many technological processes will increasingly involve the liquefaction, storage, and pumping of methane either as a pure fluid or as the major component of liquefied natural gas. Hence our ultimate objective is the determination of accurate thermodynamic properties for this fluid from room temperature down to the solid-liquid boundary, with

*This work was conducted at NBS under sponsorship of The American Gas Association. ${ }^{* *}$ Cryogenics Division, National Bureau of Standards, Boulder, Colorado 80302. emphasis on the saturated and compressed liquid states.

Analytical description of physical properties is a practical necessity for the tedious computations which must be performed to obtain a network of thermodynamic functions. In the present report we select some published properties data and place them in analytical form directly useful for thermal computations. This work is appropriate because more data are available for methane than for any fluid previously studied experimentally at this laboratory. Data from different sources on a given property seldom are completely consistent. With the increase of available data we often suffer a decrease of precision. Our new analytical descriptions, however, are powerful tools for examining raw data because they are constrained to accepted fluids behavior, especially at the critical point $[1,2]^{1}$. Their use provides a principal justification for reexamining data on methane.

Our particular objective in this and a following report is to describe the coexistence regions, because they are boundaries for $P V T$ behavior in the one-phase domain. The virial equation of state (valid at densities below one half the critical density) is treated first, however, because it will be used to estimate some coexistence data. It also provides low-density PVT "data" not available through our high-density experimental techniques.

Temperatures in this report have been converted from the 1948 to the 1968 IPTS [3] via an interpolation program provided by Rolf Prydz.

The values of fixed-point constants selected for present work are given on the first two lines of table 1 . Temperatures are on the IPTS-1968. In a following

${ }^{1}$ Figures in brackets indicate the literature references at the end of this paper. 
report on the orthobaric densities we had found $T_{c}=190.5 \pm 0.1 \mathrm{~K}$. We then discovered two new investigations of the critical region [24, 25]. Values from these publications are given on the last two lines of table 1 . Temperatures have been increased by $0.032 \mathrm{~K}$ to bring them onto IPTS-1968. To avoid proliferation of published critical-point constants we have adopted $T_{c}=190.53 \mathrm{~K}$ from [25]. Our critical-point pressure is given by the vapor pressure equation of the present report. Our critical-point density is obtained from our rectilinear diameter.

TABLE 1. Fixed-point constants for methane

\begin{tabular}{|c|c|c|c|}
\hline Fixed point & $T$ & $P$ & $d$ \\
\hline & K & atm & mol/l \\
\hline Triple point & $90.66[11]$ & 0.1151 & $28.0536 *$ \\
\hline Critical point & 190.53 & 45.346 & 10.15 \\
\hline C.P. [24] & $190.58 \pm 0.05$ & & $10.35 \pm 0.13$ \\
\hline C.P. [25] & 190.530 & 45.346 & 10.1475 \\
\hline
\end{tabular}

*Density of liquid at $T_{t}$.

\section{The Virial Coefficients}

It is convenient for correlation in corresponding states to define reduced variables $\tau \equiv T / T_{c}, \sigma \equiv d / d_{c}$. The truncated virial equation used here then is

$$
Z=1+B(\tau) \cdot \sigma+C(\tau) \cdot \sigma^{2} .
$$

The second and third virial coefficients $B(\tau), C(\tau)$ are dimensionless.

Data for $B(\tau)$ have been selected from four sources $[4,5,6,7]$. Representation of these data, needed for computations, is given by the same type of expansion as was used for hydrogen [8],

$$
B(\tau)=\sum_{i=1}^{6} B_{i} \cdot(1 / \tau)^{(2 i-1) / 4}
$$

Data were eliminated, however, if they diverged more than 1 percent. We are left with the set of points plotted on figure 1. The line is calculated from (2) with coefficients

$$
\begin{array}{ll}
B_{1}=16.67707, & B_{4}=-203.22428, \\
B_{2}=-87.41490, & B_{5}=108.550470, \\
B_{3}=187.43954, & B_{6}=-23.213116 .
\end{array}
$$

The rms relative deviation for 25 points is 0.31 percent. Individual deviations, $\Delta \equiv\left(B / B_{\text {calc }}-1\right)$, are given in percent on figure 2. Equation (2) may not be accurate for $\tau \geqslant 2$ with above coefficients.

Calculated data for $B(\tau)$ will be published by Sengers, Klein, and Gallagher using an intermolecular potential function adjusted to the experimental data

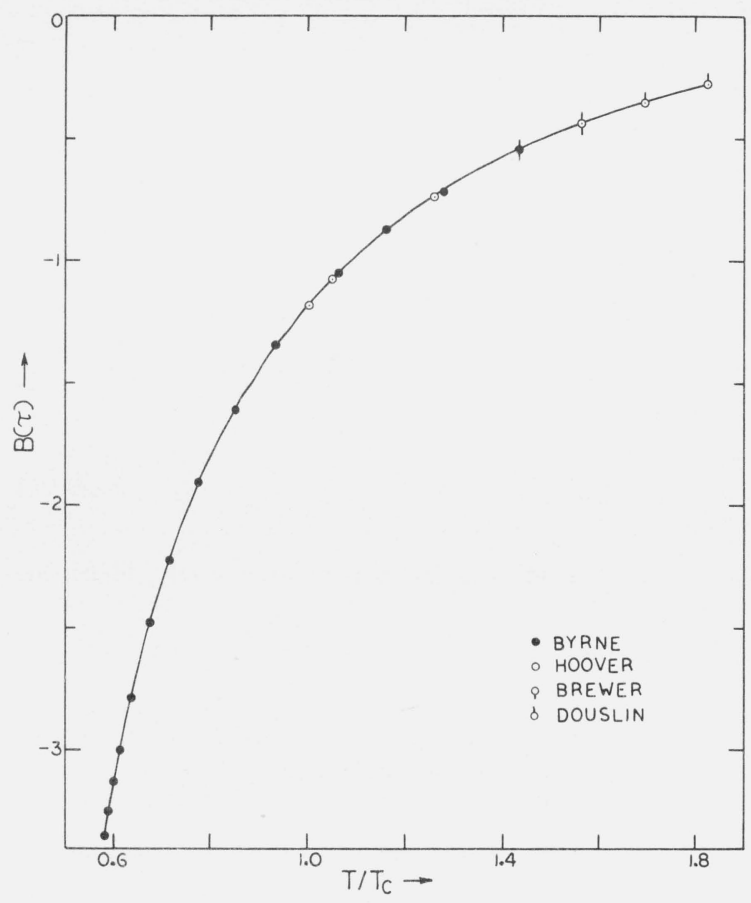

Figure 1. Second virial coefficient $\mathrm{B}(\tau)$ for methane.

These data are represented by eq (2).

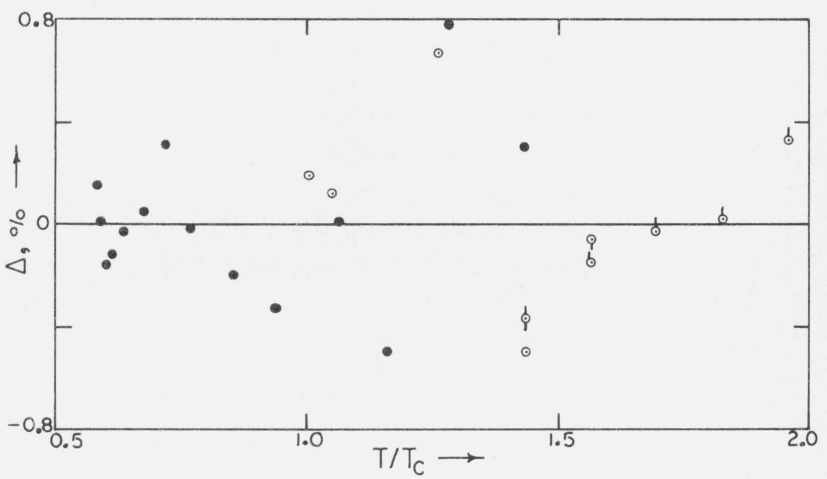

FIGURE 2. Relative deviations of second virial coefficient data from $e q$ (2).

Points are identified as on figure 1 .

[26]. For thermal computations this has the very important advantage that the temperature dependence is theoretically based, as compared with a polynomial adjusted to imprecise experimental data only. To see how drastic this may be, compare coefficients of eq (2) given above with values given below for data of [26] in the range $110 \leqslant T \leqslant 450 \mathrm{~K}$,

$$
\begin{array}{ll}
B_{1}=2.109914, & B_{4}=-16.022404, \\
B_{2}=-7.268397, & B_{5}=9.4504285, \\
B_{3}=13.088869, & B_{6}=-2.5322231 .
\end{array}
$$

The rms relative deviation for 47 data is 0.051 percent. There is no clear indication that the deviations are systematic. At $T \leqslant 200 \mathrm{~K}$ no deviation exceeds 0.02 
percent. At $T>200 \mathrm{~K}$ no deviation exceeds 0.17 percent.

For $C(\tau)$ few data are available at low temperatures. Figure 3 gives data of [5] at $\tau<1.5$, and data of [7] at $\tau>1.5$. We had devised a form for describing data on hydrogen [8], which later was modified [9], and now is further changed to obtain a better representation of these methane data,

$$
C(\tau)=\left[C_{1} / \tau^{1 / 2}+C_{2} / \tau^{5}\right] \cdot\left[1-\exp \left(1-C_{3} \cdot \tau^{2}\right)\right] .
$$

The line on figure 3 is calculated from (3) with constants,

$$
C_{1}=0.23844, \quad C_{2}=0.56243, \quad C_{3}=1.90 .
$$

The behavior given by (3) is quite similar to that of recent precise data on oxygen [10] for which a maximum value of $C(\tau)=0.50$ occurs at $\tau=0.9$. The root for oxygen is near $\tau_{0}=0.70$, whereas $C_{3}$ was selected for methane to shift this root to a slightly higher value.

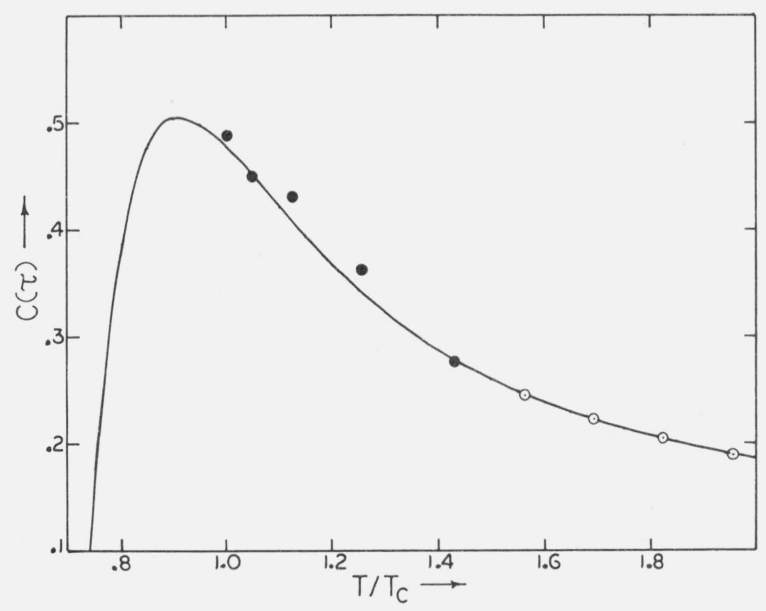

FigurE 3. Third virial coefficient $\mathrm{C}(\tau)$ for methane.

At $T / T_{c}<1.5$, the data are from [5]; above 1.5 they are from [7]. The line is calculated with eq (3).

\section{The Vapor Pressures}

The vapor pressures of liquid methane have been observed by numerous authors, giving roughly 200 $P-T$ pairs $[11, \ldots ., 16]$. Some data differ by several percent from the smoothed behavior of all data. Only by use of a reliable form of vapor-pressure equation with a minimum of arbitrary constants does it appear possible to attack this mass of data with relative confidence [1]. Our independent variable is

$$
x(T) \equiv\left(1-T_{t .} / T\right) /\left(1-T_{t} / T_{c}\right)
$$

and the new equation is

$$
\log _{e}\left(P / P_{t}\right)=a \cdot x+b \cdot x^{2}+c \cdot x^{3}+d \cdot x \cdot(1-x)^{\epsilon} .
$$

Exponent $\epsilon$ has been established at this laboratory through examination of more precise data on other substances: $\epsilon=1.433$ for fluorine [17] and $\epsilon=1.45 \pm 0.05$ for oxygen (Rolf Prydz); and $\epsilon=1.45$ for nitrogen [27].

We take $\epsilon=1.45$ for methane. At first we allowed the triple-point pressure in (4) to appear on the right as a least-squares coefficient, finding a value in agreement with [11], table 1. Thereafter we used (4) as written, constrained to the triple point. By use of (4) as a reliable smoothing function we successively eliminated inconsistent data, ending with 161 points and an rms relative deviation of 0.27 percent by use of coefficients,

$$
\begin{array}{ll}
a=4.4703915, & \quad c=-0.7444619, \\
b=2.2503526, & d=1.6017258 .
\end{array}
$$

Deviations are plotted on figure 4. Filled circles are 47 smoothed data recommended by Armstrong [11]. The remaining 114 points $(N$ pts) and their ranges are

\begin{tabular}{lcrrr}
\multicolumn{1}{c}{ Author } & & $N$ pts & & Range, $T, \mathrm{~K}$ \\
Bloomer [15] & & 17 & & $111.4-190.4$ \\
Grigor [16] & & 32 & & $98.2-188.9$ \\
Hestermans [14] & & 16 & & $117.3-189.6$ \\
Itterbeek [12] & 20 & & $149.8-190.3$ \\
Vennix [13] & & 29 & & $133.7-190.2$
\end{tabular}

\section{The Melting Pressures}

Melting pressures $P(T)$ for coexisting solid and liquid methane have been observed to $P=156[18]$ and in the range $970 \leqslant P \leqslant 2700$ atm [19]. Another three points at $P<46$ [20] agree well with [18]. The latter authors gave methane vapor pressures at their melting temperatures. We have used temperatures derived from these vapor pressures via (4). They are at most $0.03 \mathrm{~K}$ higher than those given in [18].

To examine the melting pressures we plot $Y(P, T) \equiv\left(P-P_{t}\right) /\left(T-T_{t}\right)$ versus $x \equiv T / T_{t}$ as recommended in [21], figure 5. Solidly filled circles represent data from [19] used with triple-point constants of table 1 .

For the data of [18] alone, the Simon melting equation

$$
\left(P-P_{t}\right)=P_{0} \cdot\left(x^{\epsilon}-1\right)
$$

yields an exponent $\epsilon$ in excess of 3.0, much greater than found for many other fluids [21]. The authors [19] found $\epsilon=1.01$ and rounded the triple-point temperature to $T_{t}=89 \mathrm{~K}$, making three adjusted constants. It is possible that their methane was insufficiently pure for present purposes. By adding $2 \mathrm{~K}$ to all of their temperatures, the points of figure 5 move down and to the right (large, open circles).

We now examine for comparison a possibly similar substance, argon, for which precise, independent data are available: from [22] to $P=1500$; and from [23] at $970 \leqslant P \leqslant 6000$ atm. Figure 6 gives these argon data in the same range covered by the methane data. The 

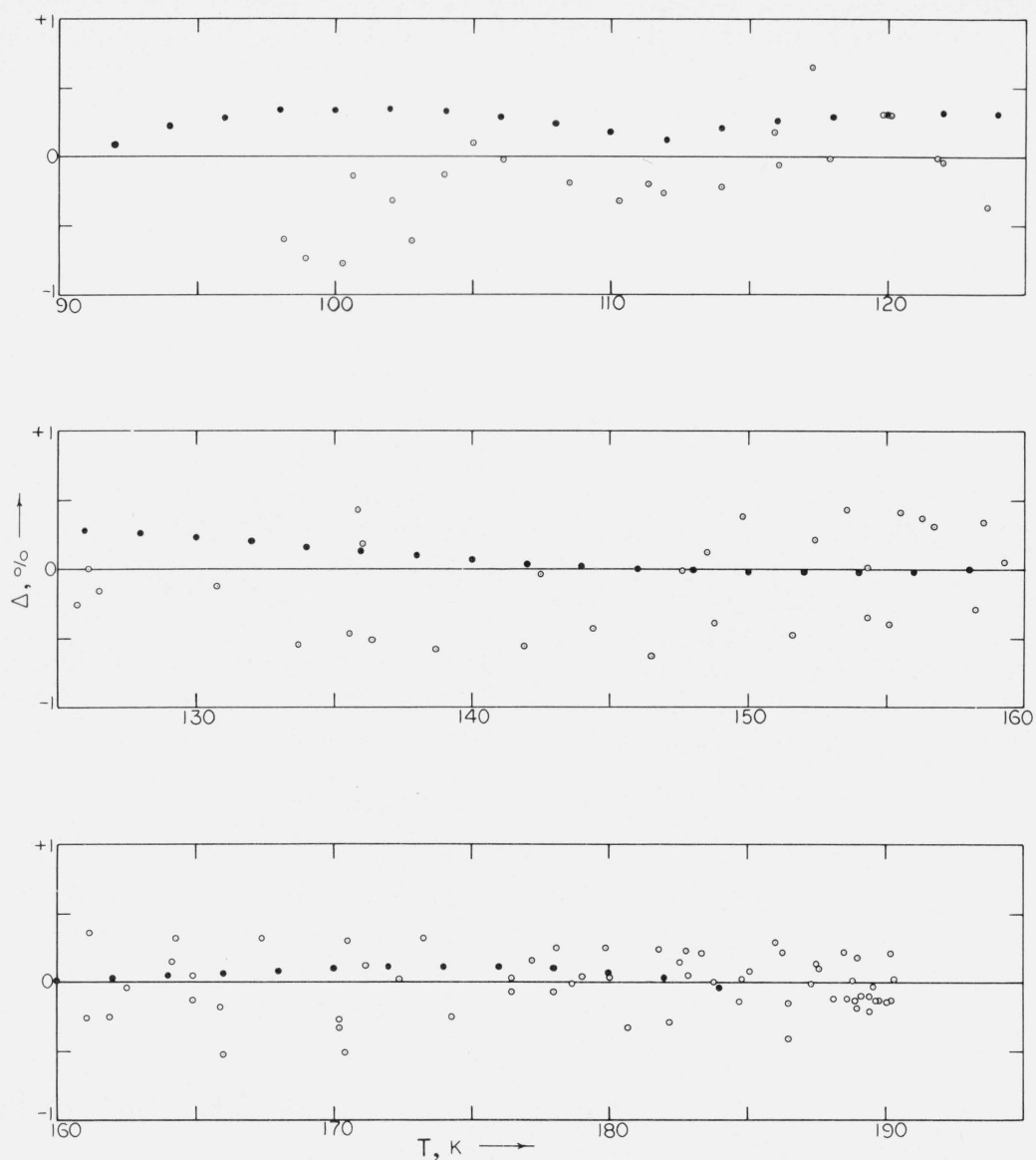

FigURE 4. Relative deviations of methane vapor pressures from eq (4).

Filled circles are from [11].

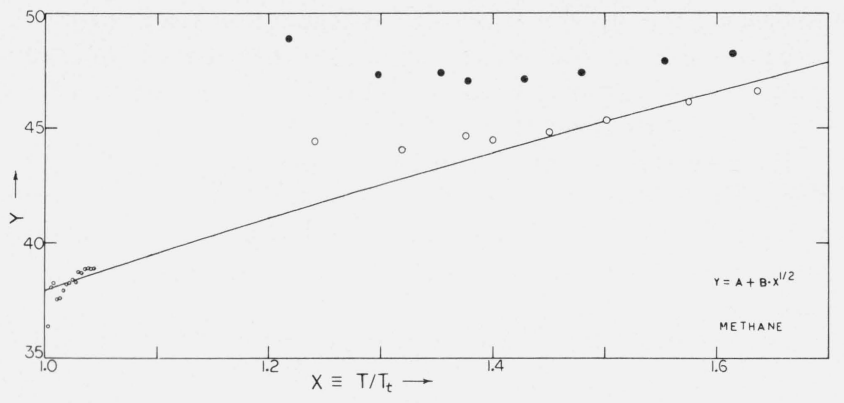

Figure 5. The melting function $\mathrm{Y} \equiv\left(\mathrm{P}-\mathrm{P}_{\mathrm{t}}\right) /\left(\mathrm{T}-\mathrm{T}_{\mathrm{t}}\right)$ for methane.

16 argon pressures are represented with an rms relative deviation of 0.091 percent by the expression

$$
\begin{aligned}
Y(P, T) & =A+B \cdot x^{\epsilon}, \\
A=21.4192, \quad B & =18.1926, \quad \epsilon=2 / 3,
\end{aligned}
$$

which was used to draw the line on figure 6 .

For methane on figure 5 we see that a greater curvature at the origin (than used for argon) should give a better representation. We arbitrarily take $\epsilon=1 / 2$, to

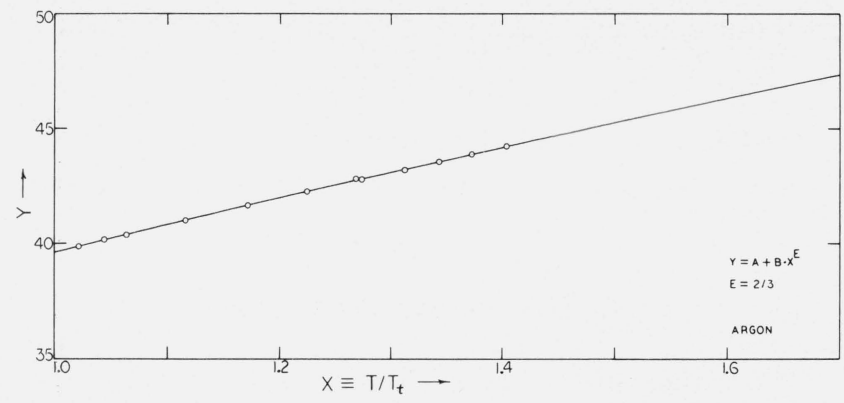

FigurE 6. The melting function $\mathrm{Y} \equiv\left(\mathrm{P}-\mathrm{P}_{t}\right) /\left(\mathrm{T}-\mathrm{T}_{\mathrm{t}}\right)$ for argon.

give the provisional melting pressure equation (6) for methane with constants

$$
A=5.318, \quad B=32.635, \quad \epsilon=1 / 2
$$

The line on figure 5 was calculated with these constants.

Melting pressures beyond our present range of interest have been observed to 24,000 atm [28]. To complete our reporting, however, we give these data on figure 7 . 


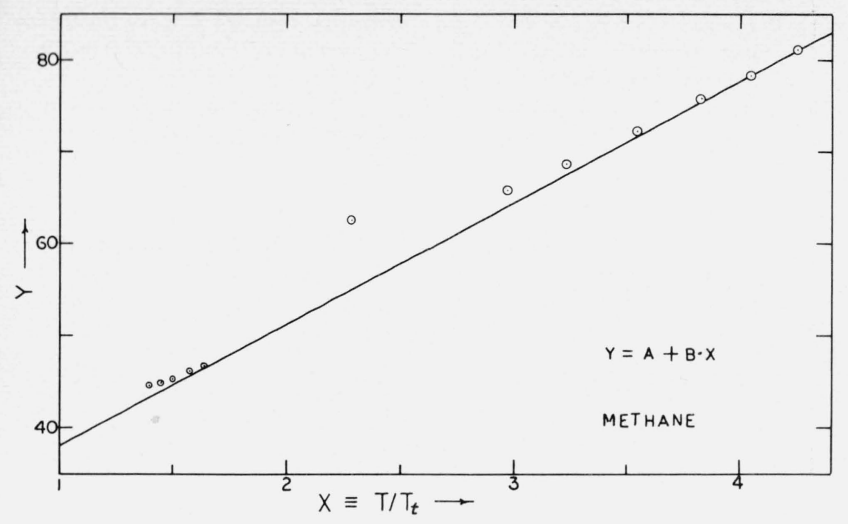

Figure 7. The melting function $\mathrm{Y} \equiv\left(\mathrm{P}-\mathrm{P}_{\mathrm{t}}\right) /\left(\mathrm{T}-\mathrm{T}_{\mathrm{t}}\right)$ for methane up to $\mathrm{P}=24,000$ atm.

Small circles are from [19]; large circles from [28]. The line is $Y=24.75+13.25 \cdot x$

\section{Conclusions}

This correlation has been undertaken to evaluate the quality of existing physical properties measurements on compressed gaseous and liquid methane, to reveal significant gaps or inconsistencies in existing measurements, and to provide accurate analytical representations of selected data for preliminary thermodynamic computations. Selected data for the second virial coefficient at temperatures down to the normal boiling point are of good quality, but few if any consistent data exist for lower temperatures. Further results for the third virial coefficient are needed at low temperatures. For the vapor pressures, the rms deviation of 0.3 percent found here could be reduced one order of magnitude through self-consistent measurements of high accuracy [17]. New determinations of the melting pressures to about 300 atm clearly are needed. Available analytical expressions are capable of representing all of the properties we have examined within the precision of the measurements.

\section{References}

\section{General Surveys}

[G1] Matthews, C. S., and Hurd, C. O., Thermodynamic properties of methane, Trans. Am. Inst. Chem. Engrs. 42, 55 (1946).

[G2] Din, F., ed., Thermodynamic Functions of Gases, Vol. 3, Ethane, Methane, Nitrogen (Butterworths Scientific Publications, London, 1961).

[G3] Edmister, W. C., Applied Hydrocarbon Thermodynamics, Vol. 1, (Gulf Publ. Co., Houston, Texas, 1961).

[G4] Guereca, R. A., Richardson, H. P., Gordon, J. L., et al., Thermophysical Properties of Selected Gases Below 300 Degrees K, Inform. Circ. No. 8317, Helium Research Center, Bureau of Mines (Amarillo, Texas, 1967).

[G5] Hall, Louise A., A Bibliography of Thermophysical Properties of Methane from 0 to $300^{\circ} \mathrm{K}$, Nat. Bur. Stand. (U.S.), Tech. Note 367 (U.S. Gov't. Printing Office, Washington, D.C. 20402, May 1968).

Mr. William J. Hall generously provided the essential least-squares and iteration programs used throughout this and earlier work by the author. Dwain E. Diller kindly made improvements in this manuscript.

\section{Specific References}

[1] Goodwin, R. D., Nonanalytic vapor pressure equation with data for nitrogen and oxygen, J. Res. Nat. Bur. Stand. (U.S.), 73A (Phys. and Chem.), No. 5, 487 (1969).

[2] Goodwin, R. D., Estimation of critical constants $T_{c}, \rho_{c}$ from the $\rho(T)$ and $T(\rho)$ relations at coexistence, J. Res. Nat. Bur. Stand. (U.S.), 74A (Phys. and Chem.), No. 2, 221 (1970).

[3] The international practical temperature scale of 1968, Metrologia 5, No. 2, 35-49 (1969).

[4] Byrne, M. A., Jones, M. R., and Staveley, L. A. K., Second virial coefficients of argon, krypton and methane and their binary mixtures at low temperatures, Trans. Faraday Soc. 64, No. 7, 1747 (1968).

[5] Hoover, A. E., Nagata, I., Leland, T. W., and Kobayashi, R., Virial coefficients of methane, ethane, and their mixtures at low temperatures, J. Chem. Phys. 48, No. 6, 2633 (1968).

[6] Brewer, Jerome, Determination of Mixed Virial Coefficients, Midwest Research Institute, Kansas City, Missouri 64110, (Dec., 1967), Defense Documentation Center No. AD-663 448.

[7] Douslin, D. R., Harrison, R. H., Moore, R. T., and McCullough, J. P., P-V-T Relations for methane, J. Chem. and Eng. Data 9, No. 3, 358 (1964).

[8] Goodwin, R. D., Diller, D. E., Roder, H. M., and Weber, L. A., Second and third virial coefficients for hydrogen, J. Res. Nat. Bur. Stand. (U.S.), 68A (Phys. and Chem.), No. 1, 121 (1964).

[9] Chueh, P. L., and Prausnitz, J. M., Third virial coefficients of nonpolar gases and their mixtures, Am. Inst. Chem. Eng. J. 13 (5), 869 (1967).

[10] Weber, Lloyd A., $P-V-T$, thermodynamic and related properties of oxygen from the triple point to $300 \mathrm{~K}$ at pressures to $33 \mathrm{MN} / \mathrm{m}^{2}$, J. Res. Nat. Bur. Stand. (U.S.), 74A (Phys. and Chem.), No. 1, 93-129 (1970).

[11] Armstrong, G. T., Brickwedde, F. G., \& Scott, R. B., Vapor pressures of the methanes, J. Res. Nat. Bur. Stand. (U.S.) 55, No. 1, 39-52 (1955).

[12] Van Itterbeek, A., Staes, K., Verbeke, O., and Theeuwes, F., Vapour pressure of saturated liquid methane, Physica 30, 1896 (1964).

[13] Vennix, Alan John, Low Temperature Volumetric Properties and the Development of an Equation of State for Methane, Thesis, Dept. of Chem. Engrn'g., Rice University, Houston, Texas, April, 1965.

[14] Hestermans, P., and White, David, The vapor pressure, heat of vaporization and heat capacity of methane from the boiling point to the critical temperature, J. Phys. Chem. 65, 362 (Feb., 1961).

[15] Bloomer, O. T., and Parent, J. D., Liquid-vapor phase behavior of the methane-nitrogen system, Chem. Eng. Prog. Symposium Ser. 6, 49, 11-24 (1952).

[16] Grigor, Anthony F., The Measurement and Correlation of Some Physical Properties of Methane and Per-deuteromethane, Thesis, Dept. of Chem., Pennsylvania State Univ., December 1966; J. Chem. Phys. 48(3), 1032 (1968).

[17] Prydz, Rolf, Straty, G. C., and Timmerhaus, K. D., Properties of fluorine along the vapor-liquid coexistence boundary, submitted to J. Chem. Phys., 1970.

[18] Clusius, K., and Weigand, K., Die Schmelzkurven der Gase $\mathrm{A}, \mathrm{Kr}, \mathrm{X}, \mathrm{CH}_{4}, \mathrm{CH}_{3} \mathrm{D}, \mathrm{CD}_{4}, \mathrm{C}_{2} \mathrm{H}_{4}, \mathrm{C}_{2} \mathrm{H}_{6}, \mathrm{COS}$, und $\mathrm{PH}_{3}$ bis 200 Atm. Druck, Z. physik. Chem. B46, No. 1, 1-37 (1940).

[19] Stryland, J. C., Crawford, J. E., and Mastoor, M. A., Melting temperatures of krypton, xenon, and methane at pressures up to $3000 \mathrm{~atm}$, Can. J. Phys. 38, 1546 (1960).

[20] Freeth, F. A., and Verschoyle, T. T. H., Physical constants of the system methane-hydrogen, Proc. Roy. Soc. (London) 130A, 453 (1931).

[21] Goodwin, R. D., and Weber, L. A., A comparison of two meltingpressure equations constrained to the triple point using data for eleven gases and three metals, Nat. Bur. Stand. (U.S.), Tech. Note 183, October 6, 1963. U.S. Gov't. Printing Office, W ashington, D.C. 20402.

[22] Michels, A., and Prins, C., The melting lines of argon, krypton, and xenon up to $1500 \mathrm{~atm}$; representation of the results by a law of corresponding states, Physica 28, 101 (1962).

[23] Bridgman, P. W., The melting curves and compressibilities of nitrogen and argon, Proc. Am. Acad. Arts Sci. 70, 1 (1935). 
[24] Ricci, F. P., and Scafè, E., Orthobaric density of $\mathrm{CH}_{4}$ in the critical region, Phys. Letters 29A, (No. 11), 650 (1969).

[25] Jansoone, V., Gielen, H., DeBoelpaep, J., and Verbeke, O. B., The pressure-temperature-volume relationship of methane near the critical point, Physica 46, 213 (1970).

[26] Sengers, J. M. H. L., Klein, Max, and Gallagher, J. S., Pressurevolume-temperature relationships of gases: Virial coefficients, to appear in a forthcoming edition of The American Institute of Physics Handbook.
[27] Weber, Lloyd A., Some vapor pressure and PVT data on nitrogen in the range $65-140 \mathrm{~K}$. The Journal of Chemical Thermodynamics (1970).

[28] Grace, J. D., and Kennedy, G. C., The melting curves of five gases to $30 \mathrm{~kb}$, J. Phys. Chem. Solids 28, 977 (1967).

(Paper 74A5-629) 